\title{
Electronic influences of bridging and chelating diimine ligand coordination in formamidinate-bridged $\mathrm{Rh}_{2}(\mathrm{II}, \mathrm{II})$ dimers
}

\author{
Travis A. White ${ }^{\mathrm{a}}$, Kim R. Dunbar ${ }^{\mathrm{b}, *}$, Randolph P. Thummel ${ }^{\mathrm{c}, *}$, and Claudia Turro ${ }^{\mathrm{a}, *}$ \\ ${ }^{a}$ Department of Chemistry and Biochemistry, The Ohio State University, Columbus, OH 43210, USA \\ ${ }^{\mathrm{b}}$ Department of Chemistry, Texas A\&M University, College Station, TX 77843, USA \\ ${ }^{\mathrm{c}}$ Department of Chemistry, University of Houston, Houston, TX 77204, USA
}

\begin{abstract}
Two new formamidinate-bridged $\mathrm{Rh}_{2}{ }^{\mathrm{IIIII}}$ complexes, cis-[ $\left[\mathrm{Rh}_{2}{ }^{\mathrm{II}, \mathrm{II}}(\mu-\mathrm{DTolF})_{2}(\mu-\mathrm{np})_{2}\right]^{2+}$ (3; $\mathrm{DTolF}=N, N^{\prime}$-di-p-tolylformamidinate; $\mathrm{np}=1,8$-naphthyridine) and $c i s-\left[\mathrm{Rh}_{2}{ }^{\mathrm{II}, \mathrm{II}}(\mu\right.$ $\left.\mathrm{DTolF})_{2}\left(\kappa^{2} \text {-dap }\right)_{2}\right]^{2+}(4 ;$ dap $=1,12$-diazaperylene $)$, were synthesized from $\left[\mathrm{Rh}_{2}{ }^{\mathrm{II}, \mathrm{II}}(\mu-\right.$ DTolF $\left.)_{2}\left(\mathrm{CH}_{3} \mathrm{CN}\right)_{6}\right]\left(\mathrm{BF}_{4}\right)_{2}(\mathbf{1})$, and their properties were compared to those of $\left[\mathrm{Rh}_{2}{ }^{\mathrm{II}, \mathrm{II}}(\mu-\right.$ $\left.\mathrm{DTolF})_{2}(\text { phen })_{2}\right]\left(\mathrm{BF}_{4}\right)_{2}$ (2). Density functional theory (DFT) and electrochemical analyses support the description of the highest occupied molecular orbitals (HOMOs) of $\mathbf{3}$ and $\mathbf{4}$ as possessing contributions from the metals and formamidinate bridging ligands, with $\mathrm{Rh}_{2} /$ form character, and lowest unoccupied molecular orbitals (LUMOs) localized on the respective diimine ligand $\mathrm{np}$ and dap $\pi^{*}$ orbitals. Both $\mathbf{3}$ and $\mathbf{4}$ display strong, low energy $\mathrm{Rh}_{2} /$ form $\rightarrow$ diimine $\left(\pi^{*}\right)$ metal/ligand-to-ligand charger transfer $\left({ }^{1} \mathrm{ML}-\mathrm{LCT}\right)$ transitions with maxima at $566 \mathrm{~nm}\left(\varepsilon=3,600 \mathrm{M}^{-1} \mathrm{~cm}^{-1}\right)$ for 3 and at $630 \mathrm{~nm}\left(\varepsilon=2,900 \mathrm{M}^{-1} \mathrm{~cm}^{-1}\right)$ for 4 in $\mathrm{CH}_{3} \mathrm{CN}$. Time dependent-DFT (TD-DFT) calculations support these assignments. The ability of both the bridging $\mathrm{np}$ and chelating dap diimine ligands to produce strong absorption of these $\mathrm{Rh}_{2}$ IIIII complexes throughout the visible region is potentially useful for the development of new photocatalysts for $\mathrm{H}_{2}$ production and photochemotherapeutics.
\end{abstract}

Keywords: dirhodium, naphthyridine, diazaperylene, light absorption, electrochemistry Introduction 
The usefulness of the excited states involving paddlewheel $\mathrm{Rh}_{2}{ }^{\mathrm{II}, \mathrm{II}}$ complexes bridged by carboxylate, amidinate, and/or carboxamidate ligands has been demonstrated in a variety of applications, including their use as phototherapeutic agents[1-6] and for charge transfer reactions in solar energy conversion systems.[7-9] For the latter, it is important that the molecules absorb a broad range of energies to maximize the capture of sunlight, from the ultraviolet to the near-IR. The Chisholm group has reported a series of quadruply-bonded $\mathrm{Mo}_{2}, \mathrm{MoW}$, and $\mathrm{W}_{2}$ complexes which, when taken together, achieve such broad absorption.[10,11] These complexes possess excited states capable of undergoing charge transfer reactions that can be applicable to solar energy conversion.[10,11] The present work focuses on the investigation of the necessary molecular characteristics of bimetallic $\mathrm{Rh}_{2}{ }^{\mathrm{II}, \mathrm{II}}$ complexes to afford strong absorption throughout the visible range within a single molecule.

The diamagnetic nature of paddlewheel $\mathrm{Rh}_{2}{ }^{\mathrm{II}, \mathrm{II}}$ complexes arises from the formation of a single metal-metal bond by two $d^{7}$ metal centers with $\sigma^{2} \pi^{4} \delta^{2} \pi^{*^{4}} \delta^{*^{2}}$ or $\sigma^{2} \pi^{4} \delta^{2} \delta^{*^{2}} \pi^{*^{4}}$ electronic configuration.[12] The electronically and spatially accessible unoccupied $\mathrm{Rh}_{2}\left(\mathrm{~d} \sigma^{*}\right)$ molecular orbitals in $\mathrm{Rh}_{2}$ II,II dimers accommodate the coordination of up to two $\sigma$-donating axial ligands, which in turn impact the energy of the $d \sigma$ and $d \sigma^{*}$ orbitals and of the $R h_{2}\left(d \pi^{*}\right) \rightarrow R h_{2}\left(d \sigma^{*}\right)$ and $\mathrm{Rh}_{2}\left(\mathrm{~d} \delta^{*}\right) \rightarrow \mathrm{Rh}_{2}\left(\mathrm{~d} \sigma^{*}\right)$ metal-centered (MC) transitions. Additionally, the degree of electron density imposed on the $\left[\mathrm{Rh}_{2}\right]^{4+}$ core by the bridging ligand also affects the energies of the molecular orbitals (MOs) in the complex. Electronic structure calculations and electrochemical measurements illustrate that amidinate bridges are more electron donating and afford a more electron-rich $\left[\mathrm{Rh}_{2}\right]^{4+}$ core than carboxylates.[13, 14] The electronic character and spatial requirements of the equatorial and axial ligands in dirhodium complexes determine the energy of the electronic transitions and the observed chemical reactivity. The ability to electronically or 
sterically tune the molecules through the modification of the ligation sphere provides a powerful tool for designing $\mathrm{Rh}_{2}{ }^{\mathrm{IIII}}$ complexes for specific applications.

Tetraformamidinate-bridged dimers $\mathrm{Rh}_{2}{ }^{\mathrm{II}, \mathrm{II}}(\mu \text {-form })_{4}$ (form $=N, N^{\prime}$-diphenylformamidinate) possess multiple accessible oxidation states, absorb ultraviolet to near-IR light, and have accessible redox-active excited states.[7-9, 13, 15-17] Excitation of the low energy absorption bands of $\mathrm{Rh}_{2}{ }^{\mathrm{IIIII}}(\mu \text {-form })_{4}$ complexes, with maxima at $\sim 870 \mathrm{~nm}\left(\sim 3,000 \mathrm{M}^{-1} \mathrm{~cm}^{-1}\right)$ populates highly reducing excited states that are able to photochemically reduce alkyl halides (RX) through an outer sphere electron transfer mechanism to generate the corresponding axially-coordinated $\mathrm{Rh}_{2}{ }^{\mathrm{II}, \mathrm{III}}(\mu \text {-form })_{4} \mathrm{X}$ product and $\mathrm{R}$ - radicals that combine to form $\mathrm{R}_{2}$.[16] A major drawback to these $\mathrm{Rh}_{2}{ }^{\mathrm{IIIII}}(\mu \text {-form })_{4}$ neutral systems is their limited solubility in polar solvents, preventing their widespread use in solar energy conversion, photocatalysis, and biological applications. The substitution of two anionic formamidinate bridging ligands for two neutral diimine ligands, NN, produces cationic complexes of the general formula $c i s-\left[\mathrm{Rh}_{2}{ }^{\mathrm{II}, \mathrm{II}}(\mu \text {-form })_{2}(\mathrm{NN})_{2}\right]^{2+} \cdot[7,18-20]$ These compounds display enhanced solubility in water and polar organic solvents, while maintaining the rich electrochemistry and redox-active excited states of the parent $\mathrm{Rh}_{2}{ }^{\mathrm{IIIII}}(\mu-$ form $)_{4}$ complexes. $[7,19,21]$ The $c i s-\left[\mathrm{Rh}_{2}{ }^{\mathrm{IIII}}(\mu-\mathrm{form})_{2}(\mathrm{NN})_{2}\right]^{2+}$ compounds investigated to date, however, exhibit absorption with maxima at $\sim 420$ and $\sim 530 \mathrm{~nm}$ that does not extend beyond 600 $\mathrm{nm}$, a feature that is detrimental for applications that require low energy visible and near-IR excitation.

To date, only a handful of formamidinate-bridged $\mathrm{Rh}_{2}{ }^{\mathrm{IIII}}$ dimers coordinated by bidentate chelating $\left(\kappa^{2}\right)$ or bridging $(\mu)$ neutral diimine ligands have been reported.[7, 18-20] The neutral diimine coordination mode is expected to impact the electronic structure and the energy of absorption of the $c i s-\left[\mathrm{Rh}_{2}{ }^{\mathrm{II}, \mathrm{II}}(\mu \text {-form })_{2}(\mathrm{NN})_{2}\right]^{2+}$ architecture and, to the best of our knowledge, 
there are no literature reports which compare bidentate chelating and bridging neutral diimine ligands in formamidinate-bridged $\mathrm{Rh}_{2}{ }^{\mathrm{IIII}}$ complexes. Herein we report the synthesis and characterization of $c i s-\left[\mathrm{Rh}_{2}{ }^{\mathrm{IIII}}(\mu-\mathrm{DTolF})_{2}(\mu-\mathrm{np})_{2}\right]^{2+}\left(\mathbf{3} ; \mathrm{DTolF}=N, N^{\prime}\right.$-di-p-tolylformamidinate, $\mathrm{np}=1,8$-naphthyridine $)$ and $c i s-\left[\mathrm{Rh}_{2}{ }^{\mathrm{IIIII}}(\mu \text {-DTolF })_{2}\left(\kappa^{2} \text {-dap }\right)_{2}\right]^{2+}(\mathbf{4} ;$ dap $=1,12$-diazaperylene $)$ with the aim of understanding how the diimine ligand coordination mode impacts the orbital energies and light absorption. The properties of $\mathbf{4}$, possessing $\kappa^{2}$-dap ligands are compared to those of $c i s-\left[\mathrm{Rh}_{2}{ }^{\mathrm{II}, \mathrm{II}}(\mu-\mathrm{DTolF})_{2}\left(\kappa^{2} \text {-phen }\right)_{2}\right]^{2+}(\mathbf{2} ;$ phen $=1,10$-phenanthroline $)$ to investigate the effect of $\pi$-delocalization of the diimine ligands on the electronic structure. The realization of $\mathrm{Rh}_{2}{ }^{\mathrm{IIII}}$ complexes with strong absorption of low-energy visible light and that are highly soluble in water and in organic polar solvents is promising for the development of functional catalysts for the reduction of $\mathrm{H}^{+}$to $\mathrm{H}_{2}$.[7, 21]

\section{Experimental Section}

Materials: All materials were used as received unless otherwise stated. $\mathrm{RhCl}_{3} \cdot 3 \mathrm{H}_{2} \mathrm{O}$ was purchased from Pressure Chemical Company, 1,10-phenanthroline (99\%), 1,5-cyclooctadiene $(\geq 99 \%)$, sodium tert-butoxide (97\%), silver tetrafluoroborate (98\%), $p$-toluidine (99\%), and acetonitrile- $d_{3}(99.8 \%$ D) from Aldrich Chemical Company, and triethyl orthoformate (98\%) was from Sigma. 1,8-Naphthyridine ( $>98 \%)$ was purchased from TCI America and electrochemical grade tetrabutylammonium hexafluorophosphate $(\geq 99.0 \%)$ was obtained from Fluka Analytical and was recrystallized from ethanol and stored in an $80{ }^{\circ} \mathrm{C}$ oven. N,N-dimethylformamide (DMF), and acetonitrile $\left(\mathrm{CH}_{3} \mathrm{CN}\right)$ were purchased from Fisher Scientific. DMF was dried over 4 $\AA$ molecular sieves prior to use. The $\mathrm{CH}_{3} \mathrm{CN}$ was distilled by refluxing over $\mathrm{CaH}_{2}$ and was stored under an $\mathrm{N}_{2}$ atmosphere prior to use. The gases $\mathrm{N}_{2}(99.998 \%), \operatorname{Ar}(99.998 \%)$ and $\mathrm{N}_{2} / \mathrm{H}_{2}$ mixture 
(95:5) were purchased from Praxair, Inc (Danbury, CT, USA). 1,12-Diazaperylene (dap)[22], $\left[\mathrm{Rh}_{2}{ }^{\mathrm{IIII}}(\mathrm{DTolF})_{2}\left(\mathrm{CH}_{3} \mathrm{CN}\right)_{6}\right]\left(\mathrm{BF}_{4}\right)_{2} \quad(\mathbf{1})[23]$ and $\left[\mathrm{Rh}_{2}{ }^{\mathrm{II}, \mathrm{II}}(\mathrm{DTolF})_{2}(\mathrm{phen})_{2}\right]\left(\mathrm{BF}_{4}\right)_{2} \quad$ (2)[19] were synthesized as previously reported.

Cis-[Rh $\left.\mathbf{R}_{2}(\boldsymbol{\mu}-\mathrm{DTolF})_{2}(\boldsymbol{\mu}-\mathrm{np})_{2}\left(\mathrm{CH}_{3} \mathbf{C N}\right)_{2}\right]\left(\mathbf{B F}_{4}\right)_{2}(3)$ : Complex $1(0.075 \mathrm{~g}, 0.070 \mathrm{mmol})$ and $\mathrm{np}$ bridging ligand $(0.020 \mathrm{~g}, 0.15 \mathrm{mmol})$ were dissolved in a round bottomed flask containing freshly distilled $\mathrm{CH}_{3} \mathrm{CN}(20 \mathrm{~mL})$. The dark orange solution was refluxed under a $\mathrm{N}_{2}$ atmosphere protected from room light for 3 hours to afford a dark purple solution and was then cooled to room temperature. A precipitate was formed by the dropwise addition of the reaction mixture into $\sim 200 \mathrm{~mL}$ of rapidly stirring diethyl ether; the dark purple solid was collected by filtration and was rinsed with diethyl ether. To ensure that no silver salts from previous steps were present, the product was dissolved in a minimal volume of $\mathrm{CH}_{3} \mathrm{CN}$ and centrifugated to remove any solid present. The resulting dark purple solution was treated with diethyl ether and the solid was collected by vacuum filtration to afford a dark purple powder. Yield $=0.056 \mathrm{~g}, 0.048 \mathrm{mmol}$ (69\%). ${ }^{1} \mathrm{H}$ NMR ( $\left.\mathrm{CD}_{3} \mathrm{CN}, 250 \mathrm{MHz}, 298 \mathrm{~K}\right) \delta / \mathrm{ppm}: 9.50$ (4H, $\left.d d, \mu-\mathrm{np}\right), 8.56$ (4H, $\left.d d, \mu-\mathrm{np}\right)$, $7.74(4 \mathrm{H}, d d, \mu-\mathrm{np}), 7.53(2 \mathrm{H}, t, \mathrm{NCHN}), 6.97(8 \mathrm{H}, d$, phenyl $\mathrm{H}$ of DTolF), $6.54(8 \mathrm{H}, d$, phenyl $\mathrm{H}$ of DTolF), 2.24 (12H, $s,-\mathrm{CH}_{3}$ of DTolF). ESI-MS(+): $\left[\mathrm{M}-2 \mathrm{BF}_{4}{ }^{-}-2 \mathrm{CH}_{3} \mathrm{CN}+\mathrm{CN}^{-}\right]^{+}, m / z=$ $938.1($ calc.: $m / z=938.2) ;\left[\mathrm{M}-2 \mathrm{BF}_{4}{ }^{-}-2 \mathrm{CH}_{3} \mathrm{CN}\right]^{2+}, m / z=456.1($ calc.: $m / z=456.1)$.

Cis- $\left[\mathbf{R h}_{2}(\mu-\mathrm{DTolF})_{\mathbf{2}}\left(\boldsymbol{\kappa}^{2}-\mathbf{d a p}\right)_{2}\left(\mathbf{C H}_{3} \mathbf{C N}\right)_{2}\right]\left(\mathbf{B F}_{4}\right)_{2}(4)$ : Complex $\mathbf{1}(0.030 \mathrm{~g}, 0.028 \mathrm{mmol})$ and dap ligand $(0.016 \mathrm{~g}, 0.063 \mathrm{mmol})$ were dissolved in a round bottomed flask containing freshly distilled $\mathrm{CH}_{3} \mathrm{CN}(20 \mathrm{~mL})$. The dark orange solution was refluxed under a $\mathrm{N}_{2}$ atmosphere protected from room light for 24 hours to afford a maroon solution, which was cooled to room temperature. A maroon solid was precipitated by drop-wise addition of the reaction mixture into $\sim 200 \mathrm{~mL}$ of rapidly stirring diethyl ether, and the powder was collected by filtration and rinsed 
with diethyl ether. To ensure that no silver salts from previous steps were present, the maroon solid was dissolved in a minimal volume of $\mathrm{CH}_{3} \mathrm{CN}$ and centrifugated to remove any solid present, the solution was treated with diethyl ether, and the solid was collected by vacuum filtration to afford a dark maroon powder. Yield $=0.029 \mathrm{~g}, 0.021 \mathrm{mmol}(75 \%) .{ }^{1} \mathrm{H}$ NMR $\left(\mathrm{CD}_{3} \mathrm{CN}, 250 \mathrm{MHz}, 298 \mathrm{~K}\right) \delta / \mathrm{ppm}: 8.31(2 \mathrm{H}, t, \mathrm{NCHN}), 8.25$ (4H, $d, \kappa^{2}$-dap), 8.09 (4H, $d, \kappa^{2}-$ dap), $7.82\left(4 \mathrm{H}, t, \kappa^{2}\right.$-dap), 7.65 (4H, $d, \kappa^{2}$-dap), $7.45\left(4 \mathrm{H}, d, \kappa^{2}\right.$-dap), $6.97(16 \mathrm{H}, m$, phenyl $\mathrm{H}$ of DTolF), $2.27\left(12 \mathrm{H}, s,-\mathrm{CH}_{3}\right.$ of DTolF). ESI-MS(+): $\left[\mathrm{M}-2 \mathrm{BF}_{4}^{-}-2 \mathrm{CH}_{3} \mathrm{CN}+\mathrm{CN}^{-}\right]^{+}, m / z=$ $1186.2($ calc.: $m / z=1186.2) ;\left[\mathrm{M}-2 \mathrm{BF}_{4}{ }^{-}-2 \mathrm{CH}_{3} \mathrm{CN}\right]^{2+}, m / z=580.1($ calc.: $m / z=580.2)$.

Methods. ${ }^{1} \mathrm{H}$ NMR spectra were measured in acetonitrile- $d_{3}\left(\mathrm{CD}_{3} \mathrm{CN}\right)$ using a Bruker DPX 250 $\mathrm{MHz}$ spectrometer at $298 \mathrm{~K}$. Chemical shifts $(\delta)$ given in ppm were referenced to the residual $\mathrm{CH}_{3} \mathrm{CN}$ solvent signal at 1.94 ppm.[24] ESI-MS data were recorded using a Bruker MicroTOF mass spectrometer by dissolving the sample in $\mathrm{CH}_{3} \mathrm{CN}$ solvent and directly injecting into the spectrometer. Electronic absorption spectra were measured using an Agilent 8453 spectrometer equipped with a diode array detector. Extinction coefficient values were measured in a $1 \times 1 \mathrm{~cm}$ quartz cuvette in $\mathrm{CH}_{3} \mathrm{CN}$. Electrochemical measurements were carried out under an inert atmosphere using a BASi model CV-50W Voltammetric Analyzer. Cyclic voltammograms (CV) were obtained using a standard three-electrode configuration with a Pt wire auxiliary electrode, glassy carbon (3 mm diameter) working electrode, and a $\mathrm{Ag} / \mathrm{AgCl}(3 \mathrm{M} \mathrm{NaCl}$ aq $)$ reference electrode in a glass tube capped with a vycor tip. Ferrocene $(\mathrm{Fc})$ was added at the end of each set of cyclic voltammetry experiments and potentials were referenced against the ferrocenium/ferrocene couple (DMF solvent: $\mathrm{E}_{1 / 2}\left(\mathrm{Fc}^{+} / \mathrm{Fc}\right)=0.55 \mathrm{~V}, \Delta \mathrm{E}_{\mathrm{p}}=90 \mathrm{mV}, \mathrm{i}_{\mathrm{p}}{ }^{\mathrm{a}} / \mathrm{i}_{\mathrm{p}}{ }^{\mathrm{c}}=1.0$; $\mathrm{CH}_{3} \mathrm{CN}$ solvent: $\left.\mathrm{E}_{1 / 2}\left(\mathrm{Fc}^{+} / \mathrm{Fc}\right)=0.44 \mathrm{~V}, \Delta \mathrm{E}_{\mathrm{p}}=70 \mathrm{mV}, \mathrm{i}_{\mathrm{p}}{ }^{\mathrm{a}} / \mathrm{i}_{\mathrm{p}}{ }^{\mathrm{c}}=1.0\right)$. Typical CVs were recorded 
using the following conditions: DMF or $\mathrm{CH}_{3} \mathrm{CN}$ solvent, $0.1 \mathrm{M} \mathrm{Bu}_{4} \mathrm{NPF}_{6}$ supporting electrolyte, $200 \mathrm{mV} / \mathrm{s}$ scan rate, $\mathrm{N}_{2}$ atmosphere, and $298 \mathrm{~K}$ temperature. Cathodic scans were performed in DMF solvent to prevent electrode surface adsorption upon multi-electron reduction of the diimine ligand.

Molecular and electronic structure calculations were performed with density functional theory (DFT) methods using the Gaussian 09 program package.[25] The B3LYP[26-28] functional along with the 6-31G* basis set were used for $\mathrm{H}, \mathrm{C}$, and $\mathrm{N}$ atoms[29] and the Stuttgart-Dresden (SDD) energy-consistent pseudo-potentials were used for Rh.[30] Computational model compounds of the $c i s-\left[\mathrm{Rh}_{2}{ }^{\mathrm{II}}(\mu-\mathrm{DTolF})_{2}(\mathrm{NN})_{2}\left(\mathrm{CH}_{3} \mathrm{CN}\right)_{2}\right]^{2+}$ complexes were generated by replacing the methyl groups with hydrogen atoms on the acetonitrile and formamidinate ligands and are labeled 2a, 3a, and 4a.[31] Optimization of full geometries was carried out with the respective programs, and orbital analysis was performed in Gaussview version 3.09.[32] Following the optimization of the molecular structures, frequency analysis was performed to confirm the existence of local minima on the potential energy surface. Electronic absorption singlet-to-singlet transitions were calculated using time-dependent DFT (TD-DFT) methods with the polarizable continuum model (PCM) that mimicked the solvation effect of $\mathrm{CH}_{3} \mathrm{CN}$ in Gaussian 09.[33]

\section{Results and Discussion}

Synthesis. The diimine-coordinated, formamidinate-bridged $\mathrm{Rh}_{2}{ }^{\mathrm{II}, \mathrm{II}}$ dimers were synthesized via a stepwise approach to permit purification at each step.[7, 19, 23, 34, 35] As depicted in Figure 1, the final step involves refluxing 1 with two equivalents of the bridging $\mathrm{np}$ or bidentate chelating dap diimine ligand in $\mathrm{CH}_{3} \mathrm{CN}$ to afford 3 as a dark purple powder (69\%) or $\mathbf{4}$ as a dark 
maroon powder $(75 \%)$, respectively. The formation of the diimine-bridged dimer was complete within $3 \mathrm{hr}$, indicating the rapid nature of the coordination of the np ligand to the dirhodium core. Conversely, a $24 \mathrm{hr}$ reaction time was required to ensure complete bidentate ligand chelation as ${ }^{1} \mathrm{H}$ NMR after $4 \mathrm{hr}$ reflux displayed a mixture of products with one and two dap ligands coordinated to the $\mathrm{Rh}_{2}{ }^{\mathrm{II}, \mathrm{II}}$ architecture. Experimental and calculated isotopic distribution patterns, along with the observed mass-to-charge ratios $(\mathrm{m} / \mathrm{z})$, were in agreement for complexes $\mathbf{3}$ and $\mathbf{4}$ with $m / z$ peaks corresponding to $\left[\mathrm{M}-2 \mathrm{BF}_{4}{ }^{-}-2 \mathrm{CH}_{3} \mathrm{CN}+\mathrm{CN}^{-}\right]^{+}$and $\left[\mathrm{M}-2 \mathrm{BF}_{4}{ }^{-}-2 \mathrm{CH}_{3} \mathrm{CN}\right]^{2+}$. Importantly, the observed isotopic distribution patterns corresponded to the loss of two $\left[\mathrm{BF}_{4}\right]^{-}$ counterions, which is consistent with the presence of two anionic formamidinate bridging ligands coordinated to a $\left[\mathrm{Rh}_{2}\right]^{4+}$ core and the overall $2+$ charge of the complexes.

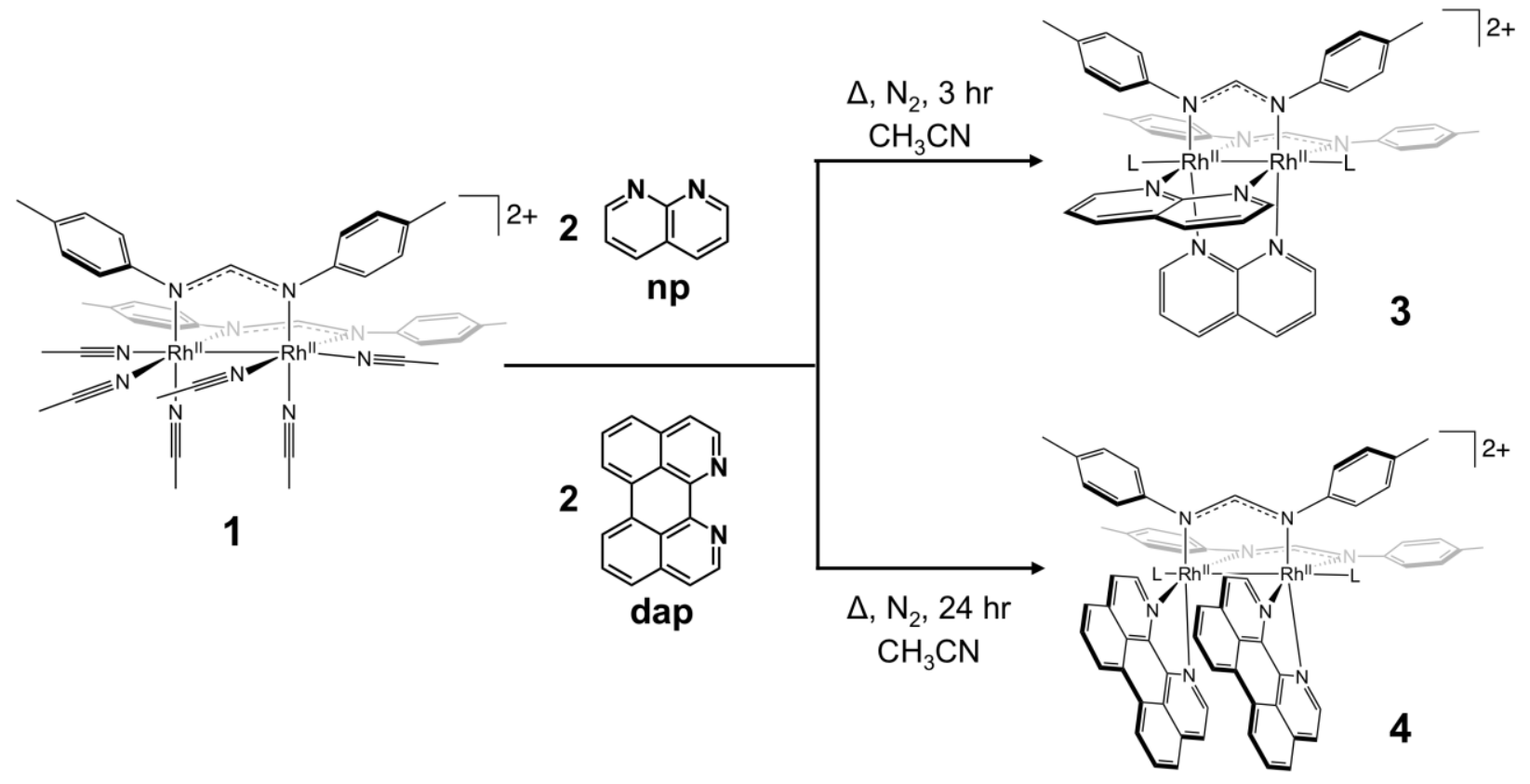

Figure 1. Synthetic scheme depicting formation of diimine-coordinated $\mathrm{Rh}_{2}{ }^{\mathrm{IIII}}$ dimers 3 and 4 (L $=\mathrm{CH}_{3} \mathrm{CN}$ solvent). 
${ }^{1} \mathrm{H}$ NMR Spectroscopy. The aromatic regions of the ${ }^{1} \mathrm{H}$ NMR spectra of $\mathbf{1}, \mathbf{3}$, and $\mathbf{4}$ in $\mathrm{CD}_{3} \mathrm{CN}$ are shown in Figure 2, revealing the symmetric nature of the $\mathrm{Rh}_{2}{ }^{\mathrm{IIII}}$ complexes as a single set of aromatic proton resonances in $\mathbf{3}$ and $\mathbf{4}$. The resonances at $\delta=7.52,7.53$, and $8.31 \mathrm{ppm}$ for $\mathbf{1}, \mathbf{3}$, and 4, respectively, correspond to the bridging $-\mathrm{NCHN}$ - methine proton in each complex, with a triplet splitting that arises from symmetric coupling of the proton with two ${ }^{103} \mathrm{Rh}$ centers $\left({ }^{3} J_{\mathrm{Rh}-\mathrm{H}}=\right.$ 3.7 $\mathrm{Hz}$ ), indicating that the bridging formamidinate ligands are chemically and magnetically equivalent.[19, 20, 23] A large downfield shift of the methine proton signal ( $\Delta \delta=0.79 \mathrm{ppm})$ from 1 to 4 is observed, which compares well with the corresponding resonances from $\delta=8.17$ ppm to $8.34 \mathrm{ppm}$ previously reported for the bidentate chelating $c i s-\left[\mathrm{Rh}_{2}{ }^{\mathrm{IIII}}(\mu-\mathrm{DTolF})_{2}\left(\kappa^{2}-\right.\right.$ $\left.\mathrm{NN})_{2}\right]^{2+}$ complexes, where $\mathrm{NN}=$ bpy $\left(2,2^{\prime}\right.$-bipyridine), phen, dpq (dipyrido[3,2-f:2',3'-h]quinoxaline), dppz (dipyrido[3,2-a:2',3'-c]phenazine), and dppn (benzo[i]dipyrido[3,2-a:2',3'h]quinoxaline).[7, 19, 20] Conversely, the methine proton signal displays a minimal or negligible $\operatorname{shift}(\Delta \delta=0.01 \mathrm{ppm})$ from 1 to 3 , in accord with the previously reported bridging compound cis$\left[\mathrm{Rh}_{2}{ }^{\mathrm{IIII}}(\mu-\mathrm{DTolF})_{2}(\mu-\mathrm{NN})_{2}\left(\mathrm{O}_{2} \mathrm{CCF}_{3}\right)_{2}\right](\mathrm{NN}=$ pyridopyrazine $)$.[18] The 1:2 ratio of $-\mathrm{NCHN}-$ methine protons to diimine protons further confirms the coordination of two diimine ligands to the $\mathrm{Rh}_{2}{ }^{\mathrm{IIII}}$ formamindinate-bridged architecture. Methyl protons from the DTolF formamidinate bridging ligands appear within the narrow upfield range of $\delta=2.24$ to $2.27 \mathrm{ppm}$ for all three complexes, indicating that ligand coordination does not largely impact the peripheral formamidinate methyl protons.[36] 


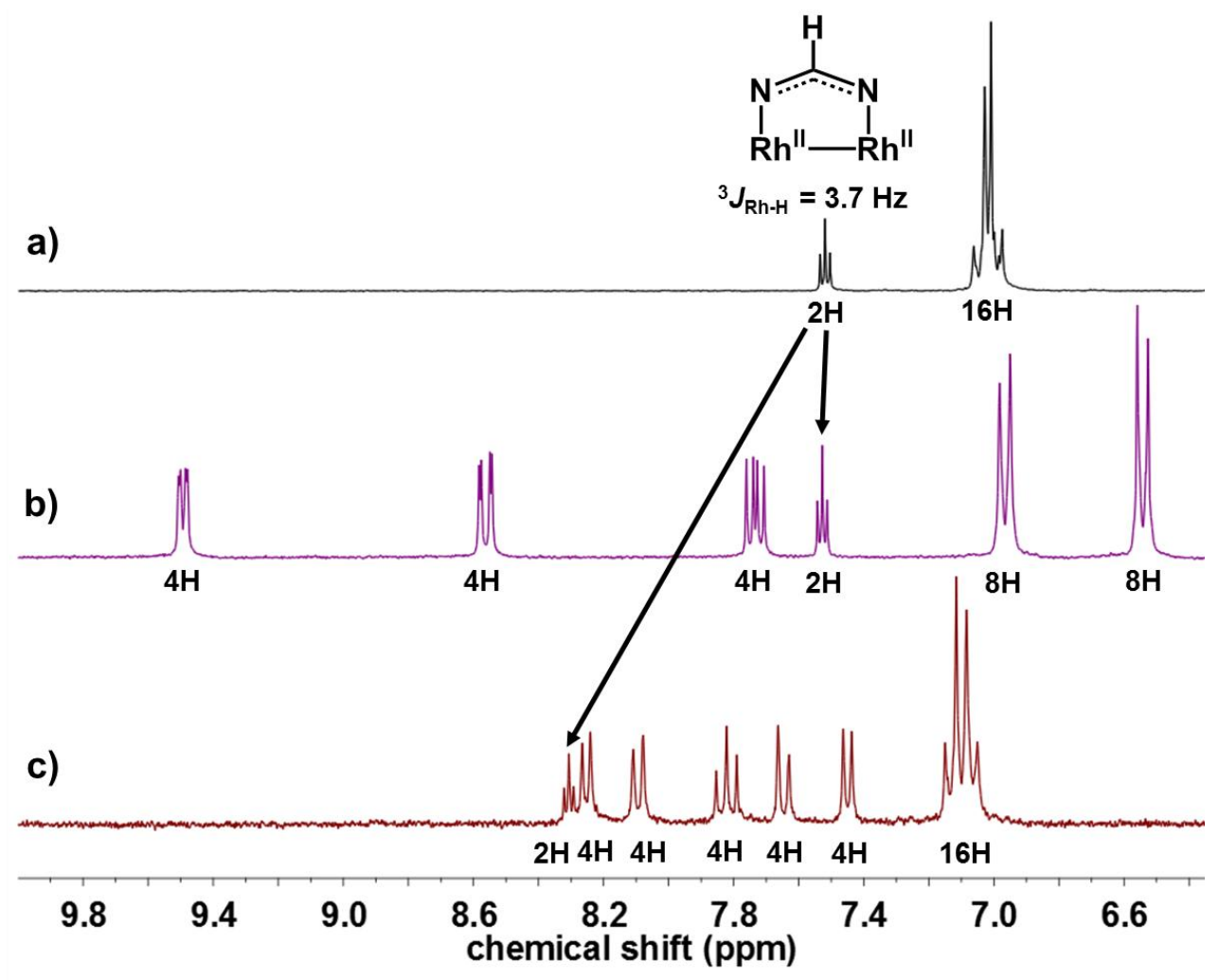

Figure 2. ${ }^{1} \mathrm{H}$ NMR spectra of (a) 1, (b) 3, and (c) 4 at $298 \mathrm{~K}$ in $\mathrm{CD}_{3} \mathrm{CN}$ displaying aromatic proton resonances; arrows indicate the chemical shift of $-\mathrm{NCHN}-$ methine proton.

Electrochemistry. Electrochemical analyses provide useful information regarding the frontier molecular orbital energies and chemical reactivity of the formamidinate-bridged $\mathrm{Rh}_{2}{ }_{2}^{\mathrm{II}, \mathrm{II}}$ compounds. In general, the electrochemical properties of $\mathbf{2}$ and $\mathbf{4}$ are similar to those of related diimine chelated dirhodium complexes, such as the $\left[\mathrm{Rh}_{2}(\mathrm{DTolF})_{2}(\mathrm{NN})_{2}\right]^{2+}(\mathrm{NN}=\mathrm{dpq}$, dppz, dppn) series.[7] Anodic scans reveal the presence of reversible redox couples at $\mathrm{E}_{1 / 2}=+0.57 \mathrm{~V}$ vs $\mathrm{Fc}^{+} / \mathrm{Fc}$ in $\mathrm{CH}_{3} \mathrm{CN}$ for both 2 and 4 and at $+0.46 \mathrm{~V}$ for $3\left(\Delta \mathrm{E}_{\mathrm{p}}=70 \mathrm{mV}, \mathrm{i}_{\mathrm{p}}{ }^{\mathrm{a}} / \mathrm{i}_{\mathrm{p}}{ }^{\mathrm{c}}=1.1\right.$, Table 1$)$. Near unity values of the peak current ratios $\left(\mathrm{i}_{\mathrm{p}}{ }^{\mathrm{a}} / \mathrm{i}_{\mathrm{p}}{ }^{\mathrm{c}}\right)$ and similar peak potential separations $\left(\Delta \mathrm{E}_{\mathrm{p}}\right)$ to that of ferrocene indicate that both complexes produce chemically stable species with reversible heterogeneous electron transfer kinetics.[37, 38] This oxidation is assigned to the 
$\mathrm{Rh}_{2}{ }^{\text {IIIIIIIIIII,II }}$ couple, expected to be at a similar potential in the chelated complexes $\mathbf{2}$ and $\mathbf{4}$, and is slightly shifted in the tetra-bridged complex 3. Further anodic scanning displays an electrochemically quasi-reversible redox couple at $\mathrm{E}_{1 / 2}=+1.02 \mathrm{~V}\left(\Delta \mathrm{E}_{\mathrm{p}}=110 \mathrm{mV}\right)$ and $\mathrm{E}_{1 / 2}=$ $+1.06 \mathrm{~V}\left(\Delta \mathrm{E}_{\mathrm{p}}=160 \mathrm{mV}\right)$ for $\mathbf{3}$ and $\mathbf{4}$, respectively. Complex 4, which contains bidentate chelating dap ligands, exhibits a quasi-reversible, one-electron reduction at $\mathrm{E}_{1 / 2}=-0.80 \mathrm{~V} v \mathrm{~s}$ $\mathrm{Fc}^{+} / \mathrm{Fc}$; this reversible couple is observed at $-0.88 \mathrm{~V} v s \mathrm{Fc}^{+} / \mathrm{Fc}$ for 2 . Similar results were reported for the $c i s-\left[\mathrm{Rh}_{2}{ }^{\mathrm{IIII}}(\mu-\mathrm{DTolF})_{2}\left(\kappa^{2}-\mathrm{NN}\right)_{2}\right]^{2+}(\mathrm{NN}=\mathrm{dppn}, \mathrm{dppz}, \mathrm{dpq}$, phen) series, for which this wave was ascribed to the $\mathrm{Rh}_{2}{ }^{\mathrm{IIIIIIIIIIII}}$ redox process.[7, 21] Unlike the case for $\mathbf{2}$ and $\mathbf{4}$, the $\mathrm{Rh}_{2}{ }^{\mathrm{III}, \mathrm{I} / \mathrm{IIIII}}$ couple in 3 is irreversible and appears at $\mathrm{E}_{\mathrm{p}}{ }^{\mathrm{c}}=-1.13 \mathrm{~V} v s \mathrm{Fc}^{+} / \mathrm{Fc}$ in $\mathrm{CH}_{3} \mathrm{CN}$. This wave is not observed in DMF in the experimental window. The disparity in the two solvents is attributed to the different strengths of axial coordination between $\mathrm{CH}_{3} \mathrm{CN}$ and DMF. In DMF, the quasi-reversible, one-electron $\mathrm{Rh}_{2}{ }^{\mathrm{IIIIIIIIIIII}}$ couples for $\mathbf{2}$ and $\mathbf{4}$ appear at $\mathrm{E}_{1 / 2}=-0.94 \mathrm{~V}$ and -0.76 $\mathrm{V} v s \mathrm{Fc}^{+} / \mathrm{Fc}$, respectively.

The couples at $-1.06 \mathrm{~V}$ and $-1.39 \mathrm{~V} v s \mathrm{Fc}^{+} / \mathrm{Fc}$ for 4 in DMF correspond to the sequential one-electron reduction of each dap-based $\pi^{*} \mathrm{MO}, \mathrm{E}_{1 / 2}\left(\mathrm{dap}^{0 /-}\right)$. These values appear at more positive potentials than those for the phen-based reduction processes in $\mathbf{2}$, at $-1.63 \mathrm{~V} v s \mathrm{Fc}^{+} / \mathrm{Fc}$ (Table 1). The dap reduction potentials in $\mathbf{4}$ compare well to those previously reported for the $\left[\mathrm{Ru}(\mathrm{bpy})_{n}(\mathrm{dap})_{3-n}\right]^{2+}(\mathrm{n}=0,1,2,3)$ series.[22] In addition, the difference between the phen and dap reduction potentials in $\mathbf{2}$ and $\mathbf{4}$ is $\sim 0.6 \mathrm{~V}$, which is similar to that measured for related $\mathrm{Ru}$ (II) complexes.[22, 39] The first reductive process for the np-bridged complex 3 in DMF is observed at a significantly more negative potential, $\mathrm{E}_{1 / 2}=-1.39 \mathrm{~V} v s \mathrm{Fc}^{+} / \mathrm{Fc}$, and is assigned to the $\mathrm{np}^{0 /-}$ couple, which compares well to that reported for $\left[\mathrm{Rh}_{2}\left(\mathrm{O}_{2} \mathrm{CCH}_{3}\right)_{2}(\mathrm{np})_{2}\right]^{2+}$ at $-1.26 \mathrm{~V} v s \mathrm{Fc}^{+} / \mathrm{Fc}$ in $\mathrm{CH}_{3}$ CN.[40] This value is $\sim 0.4 \mathrm{~V}$ more negative than that of a related complex 
$\left[\mathrm{Rh}_{2}\left(\mathrm{O}_{2} \mathrm{CCH} 3\right)_{2}(\text { pynp })_{2}\right]^{2+}$ (pynp $=2$-(2-pyridyl)-1,8-naphthyridine), -1.03 $\mathrm{V} v \mathrm{~s} \mathrm{Fc}^{+} / \mathrm{Fc}[41]$, as expected from the calculated energy differences of the unoccupied MOs of np and pynp complexes.[40] Continued cathodic scanning of $\mathbf{3}$ results in a one-electron, irreversible couple at $\mathrm{E}_{\mathrm{p}}{ }^{\mathrm{c}}=-1.57 \mathrm{~V} v s \mathrm{Fc}^{+} / \mathrm{Fc}$, corresponding to the second $\mathrm{np}^{0 /-}$ reduction, which must be followed by a chemical reaction or major structural rearrangement.

Table 1. Cyclic Voltammetric Data for Formamidinate-Bridged Dirhodium Complexes

\begin{tabular}{ccc}
\hline Complex & $\mathrm{E}_{1 / 2} / \mathrm{V}\left(\Delta \mathrm{E}_{\mathrm{p}} / \mathrm{mV}\right)^{a}$ & $\mathrm{E}_{1 / 2} / \mathrm{V}\left(\Delta \mathrm{E}_{\mathrm{p}} / \mathrm{mV}\right)^{b}$ \\
\hline $\mathbf{2}$ & $+1.06(160),+0.57(70),-0.88(80)$ & $-0.94(75),-1.63(72)$ \\
$\mathbf{3}$ & $+1.02(110),+0.46(70),-1.13^{c}$ & $-1.39(80),-1.57^{c}$ \\
$\mathbf{4}$ & $+1.06(150),+0.57(70),-0.80(80)$ & $-0.76(80),-1.06(73),-1.39(83)$ \\
\hline${ }^{\mathrm{a}} v s \mathrm{Fc}^{+} / \mathrm{Fc}\left(\mathrm{E}_{1 / 2}=+0.44 \mathrm{~V} v s \mathrm{Ag} / \mathrm{AgCl}\right.$ in $\mathrm{CH}_{3} \mathrm{CN}, 0.1 \mathrm{M} \mathrm{Bu}_{4} \mathrm{NPF}_{6}{ }^{b} v s \mathrm{Fc}^{+} / \mathrm{Fc}\left(\mathrm{E}_{1 / 2}=+0.55 \mathrm{~V} v s\right.$ \\
$\mathrm{Ag} / \mathrm{AgCl}$ in DMF, $0.1 \mathrm{M} \mathrm{Bu}_{4} \mathrm{NPF}_{6} \cdot{ }^{c}$ Reported $\mathrm{E}_{\mathrm{p}}{ }^{c}$ value.
\end{tabular}

Electronic Structure Calculations. DFT and TD-DFT computational studies were performed on the model complexes $c i s-\left[\mathrm{Rh}_{2}^{\mathrm{II}, \mathrm{II}}(\mu \text {-form })_{2}\left(\kappa^{2}-\text { phen }\right)_{2}(\mathrm{HCN})_{2}\right]^{2+}(\mathbf{2 a}), c i s-\left[\mathrm{Rh}_{2}{ }^{\mathrm{IIII}}(\mu-\text { form })_{2}(\mu-\right.$ $\left.\mathrm{np})_{2}(\mathrm{HCN})_{2}\right]^{2+}(\mathbf{3 a})$, and $c i s-\left[\mathrm{Rh}_{2}{ }^{\mathrm{IIIII}}(\mu \text {-form })_{2}\left(\kappa^{2}-\mathrm{dap}\right)_{2}(\mathrm{HCN})_{2}\right]^{2+}$ (4a) to provide information on how ligand coordination mode impacts the molecular orbital energies.[42] The resulting MO diagrams are shown in Figure 3 and the electron density maps of the HOMO and LUMO of each complex are depicted in Figure 4. The HOMO and HOMO-1 of 2a - 4a possess significant $\mathrm{Rh}_{2} /$ form character and complex 4a displays stabilization of the HOMO compared to 3a by 0.51 eV. The HOMO-2 and HOMO-3 of $\mathbf{4 a}$ are occupied dap $\pi$-based MOs, while those of 3a have $\mathrm{Rh}_{2}\left(\pi^{*}\right)$ character. Interestingly, the shift of the coordination mode from bidentate chelating in 4a to bridging in 3a does not significantly alter the calculated electronic structure (Figure 3). The electron density of the LUMO and LUMO+1 of $4 \mathbf{a}$ are localized on the dap $\pi^{*}$ orbitals, a 
finding that compares well with related complexes previously reported, including the series cis$\left[\mathrm{Rh}_{2}{ }^{\mathrm{IIII}}(\mu-\mathrm{DTolF})_{2}\left(\kappa^{2}-\mathrm{NN}\right)_{2}\right]^{2+}(\mathrm{NN}=\mathrm{dppn}, \mathrm{dppz}, \mathrm{dpq})$.[7] It is interesting to note that the daplocalized reduction occurs at a potential similar to other dap-containing complexes and the LUMO is calculated to be centered on that ligand. In the case of $\mathbf{3 a}$, however, the LUMO is calculated at a similar energy as that of $\mathbf{4 a}$, but experimentally $\mathbf{3}$ is more difficult to reduce than 4. The origin of this discrepancy remains unknown, but it is possible that there is greater orbital mixing between the unoccupied np bridging ligand orbitals and the filled metal-based MOs in $\mathbf{3}$ than the calculations predict.

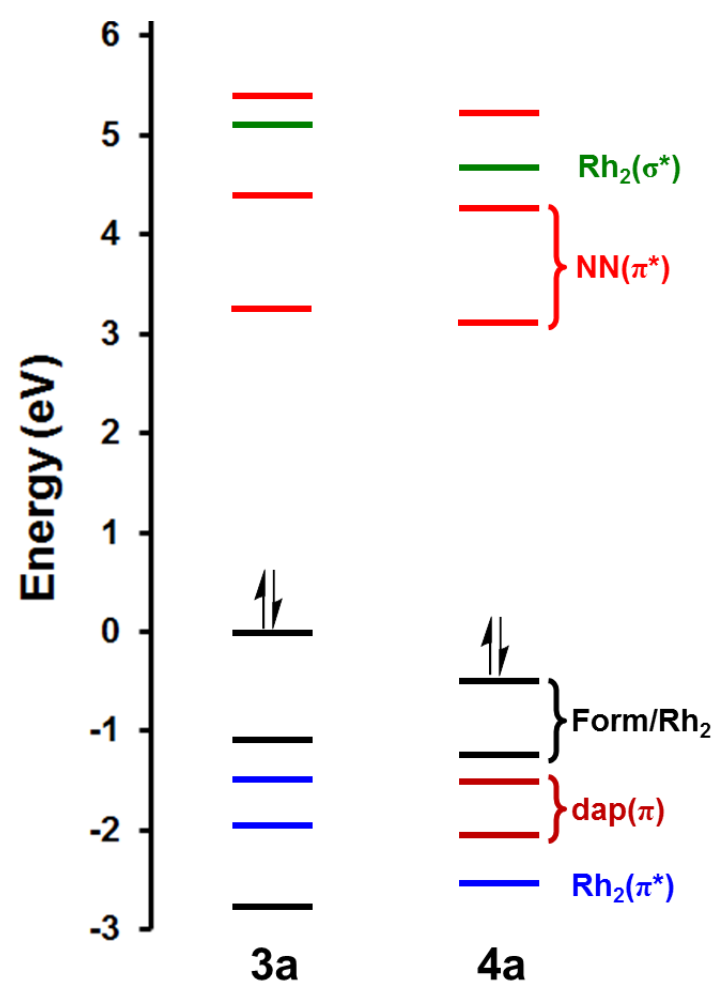

Figure 3. Calculated MO diagrams for 3a and 4a. The HOMO of 3a was arbitrarily set to $0.0 \mathrm{eV}$ 
LUMO
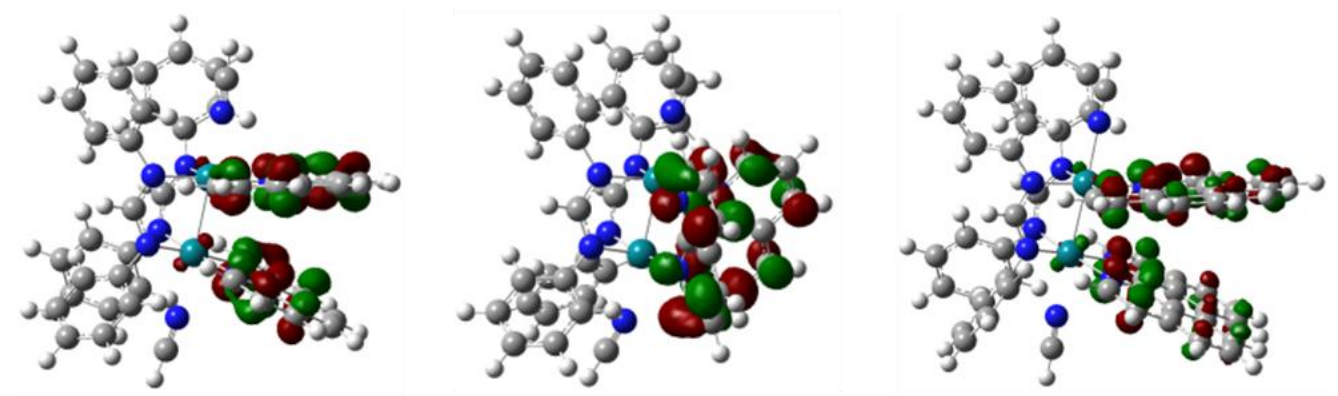

HOMO

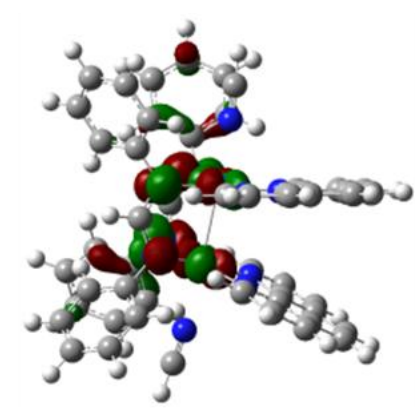

$2 a$

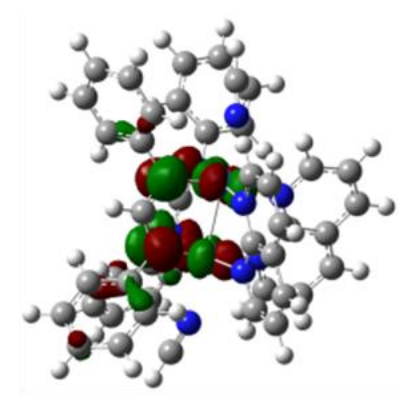

$3 a$

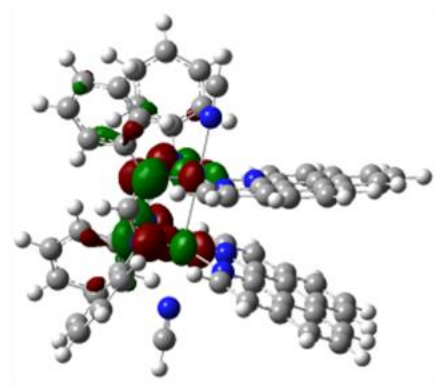

$4 a$

Figure 4. Calculated electron density maps displaying contribution to HOMO and LUMO for complexes $\mathbf{2 a}, \mathbf{3 a}$, and $\mathbf{4 a}$ drawn with isovalue $=0.04$.

The calculated low-lying singlet excited states of $\mathbf{2 a}-\mathbf{4 a}$ and the corresponding orbital transition parentages are shown in Figure 5. In 3a and 4a, the lowest energy singlet excited states are composed of $\mathrm{HOMO} \rightarrow \mathrm{LUMO}$ transitions, from the $\mathrm{Rh}_{2} /$ form-based $\mathrm{MO}$ to the corresponding unoccupied $\mathrm{NN}\left(\pi^{*}\right)$ orbitals. The results of these calculations are in agreement with those of the related $c i s-\left[\mathrm{Rh}_{2}{ }^{\mathrm{II}, \mathrm{II}}(\mu-\mathrm{DTolF})_{2}\left(\kappa^{2}-\mathrm{NN}\right)_{2}\right]^{2+}$ complexes $(\mathrm{NN}=\mathrm{dppn}, \mathrm{dppz}, \mathrm{dpq})$ for which the lowest energy transition was assigned as metal/ligand-to-ligand charge transfer $\left({ }^{1} \mathrm{ML}-\mathrm{LCT}\right)$ given the large contribution from formamidinate and $\mathrm{Rh}_{2} \mathrm{MOs}$.[7] In contrast, the lowest energy transition of $\mathbf{2 a}$ is mostly metal-centered $\mathrm{Rh}_{2} /$ form $\rightarrow \mathrm{Rh}_{2}\left(\sigma^{*}\right)$, calculated at 592 $\mathrm{nm}$, followed by ${ }^{1} \mathrm{ML}-\mathrm{LCT} \mathrm{Rh}_{2} /$ form $\rightarrow$ phen at $532 \mathrm{~nm}$. The higher energy $\mathrm{Rh}_{2}$-diimine ligand ${ }^{1}$ ML-LCT transition in 2 relative to that of $\mathbf{4}$ (Figure 5) is consistent with the ease of reduction of 
dap ligand as compared to phen (Table 1); these results are in agreement with those previously reported for related $\mathrm{Ru}(\mathrm{II})$ complexes.[22]

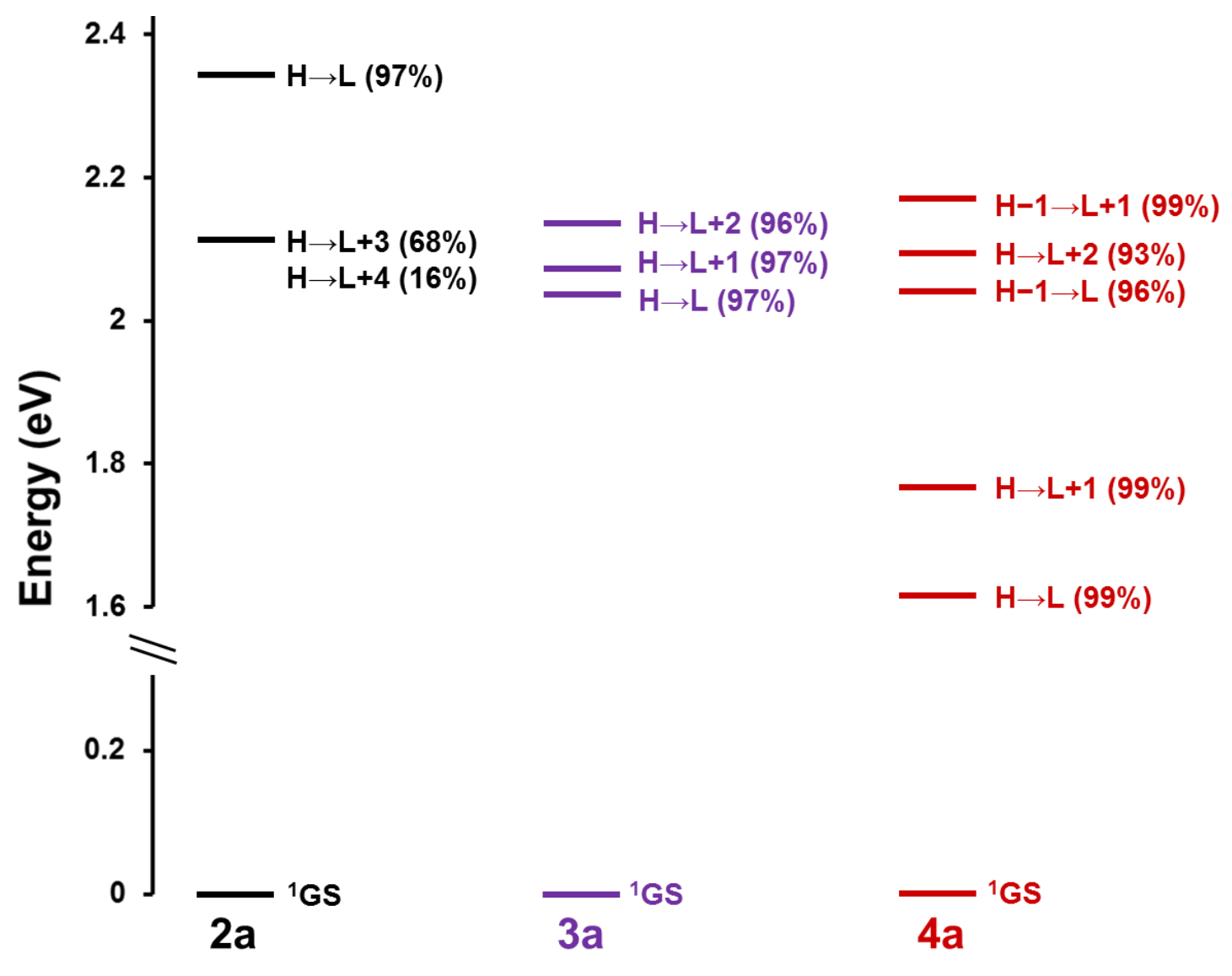

Figure 5. Calculated lowest energy singlet-to-singlet transitions for complexes 2a, 3a, and 4a. H $=\mathrm{HOMO}, \mathrm{L}=\mathrm{LUMO}, \mathrm{GS}=$ ground state.

Electronic Absorption Spectroscopy. The electronic absorption spectra of $\mathbf{3}$ and $\mathbf{4}$ are shown in Figure 6 and exhibit features in the ultraviolet (UV) and visible regions that are characteristic of formamidinate-bridged $\mathrm{Rh}_{2}{ }^{\mathrm{II}}$ dimeric architectures; the data are summarized in Table 2 . The absorption bands in the UV region are predominately intraligand ${ }^{1} \pi \pi^{*}$ transitions $\left({ }^{1} \mathrm{IL}\right)$ occurring within each diimine $\pi$ system, since their energy and molar absorptivity values are similar to 
those of the corresponding free ligand. Complex 3 displays $n p{ }^{1} \pi \pi^{*}{ }^{1} \mathrm{IL}$ transitions with maxima at $300 \mathrm{~nm}\left(\varepsilon=24,900 \mathrm{M}^{-1} \mathrm{~cm}^{-1}\right)$, a value that agrees with other transition metal complexes coordinated to np.[40, 43] The dap-containing complex 4 exhibits dap ${ }^{1} \pi \pi^{*}{ }^{1} \mathrm{IL}$ transitions with maxima at $262 \mathrm{~nm}\left(\varepsilon=79,500 \mathrm{M}^{-1} \mathrm{~cm}^{-1}\right)$ and $318 \mathrm{~nm}\left(\varepsilon=30,300 \mathrm{M}^{-1} \mathrm{~cm}^{-1}\right) \cdot[22,44]$

In the visible region, the np-bridged complex 3 exhibits two well-resolved transitions with maxima at $436 \mathrm{~nm}\left(\varepsilon=1,800 \mathrm{M}^{-1} \mathrm{~cm}^{-1}\right)$ and $566 \mathrm{~nm}\left(\varepsilon=3,600 \mathrm{M}^{-1} \mathrm{~cm}^{-1}\right)$, both assigned as arising from $\mathrm{Rh}_{2} /$ form $\rightarrow \mathrm{np}\left(\pi^{*}\right)$ metal/ligand-to-ligand charge transfer ${ }^{1}$ ML-LCT transitions based on the TD-DFT calculations. The absorption spectrum of 4 encompasses a wide range of visible light wavelengths with relatively high molar absorptivity values. The sharp peak at 414 $\mathrm{nm}\left(\varepsilon=15,800 \mathrm{M}^{-1} \mathrm{~cm}^{-1}\right)$ corresponds to a dap ${ }^{1} \pi \pi^{*}{ }^{1} \mathrm{IL}$ transition and is similar to those of other dap-containing complexes.[22, 44] The low-energy transition at $630 \mathrm{~nm}\left(\varepsilon=2,900 \mathrm{M}^{-1} \mathrm{~cm}^{-1}\right)$ corresponds to the $\mathrm{Rh}_{2} /$ form $\rightarrow \operatorname{dap}\left(\pi^{*}\right){ }^{1}$ ML-LCT transition based on the analogous cis$\left[\mathrm{Rh}_{2}{ }^{\mathrm{IIII}}(\mu-\mathrm{DTolF})_{2}\left(\kappa^{2}-\mathrm{NN}\right)_{2}\right]^{2+}$ series $(\mathrm{NN}=\mathrm{dppn}, \mathrm{dppz}, \mathrm{dpq})$ for which the lowest energy absorption is dependent on the identity of the $\mathrm{NN}$ ligand.[7] The experimental bathochromic shift observed in the maxima of the lowest energy absorption band from 3 to $4, \Delta \mathrm{E}_{\exp }=0.22 \mathrm{eV}$, is consistent with the results from TD-DFT calculations with the expected bathochromic shift of $\Delta \mathrm{E}_{\text {calc }}=0.42 \mathrm{eV}$ between 3a and 4a. Although both complexes absorb throughout the UV and visible light ranges, 4 exhibits stronger and broader absorption throughout the entire range and into the near-IR, a feature that is required to maximize the photons absorbed from sunlight for solar energy conversion applications. 
Table 2. Electronic Absorption Maxima, Extinction Coefficients, and Transition Assignments for 3 and 4 in $\mathrm{CH}_{3} \mathrm{CN}$.

\begin{tabular}{ccc}
\hline Complex & $\lambda_{\text {abs }} / \mathrm{nm}\left(\varepsilon / \times 10^{-3} \mathrm{M}^{-1} \mathrm{~cm}^{-1}\right)$ & Assignment \\
\hline 3 & $300(24.9)$ & $\mathrm{np}^{1} \pi \pi^{*}$ \\
& $436(1.8)$ & $\mathrm{Rh}_{2} /$ form $\rightarrow \mathrm{np}\left(\pi^{*}\right)$ \\
& $566(3.6)$ & $\mathrm{Rh}_{2} /$ form $\rightarrow \mathrm{np}\left(\pi^{*}\right)$ \\
& $262(79.5), 318(\mathrm{sh}, \sim 30.3)$ & $\operatorname{dap~}^{1} \pi \pi^{*}$ \\
4 & $414(15.8)$ & $\operatorname{dap}^{1} \pi \pi^{*}$ \\
& $504(12.0)$ & $\mathrm{Rh}_{2} /$ form $\rightarrow$ dap $\left(\pi^{*}\right)$, dap ${ }^{1} \pi \pi^{*}$ \\
& $630(2.9)$ & $\mathrm{Rh}_{2} /$ form $\rightarrow$ dap $\left(\pi^{*}\right)$ \\
\hline
\end{tabular}

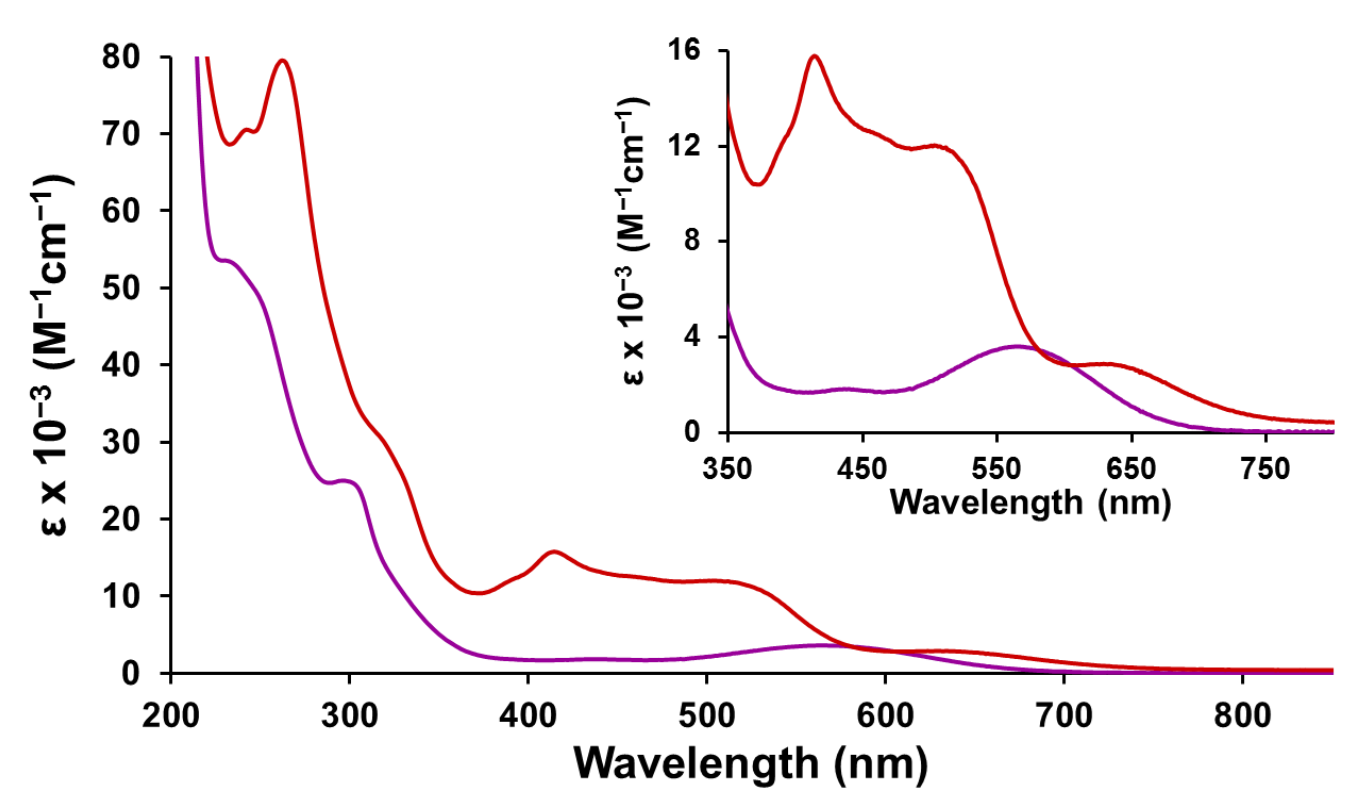

Figure 6. Electronic absorption spectra of 3 (purple line) and 4 (red line) in $\mathrm{CH}_{3} \mathrm{CN}$ solvent at room temperature using a $1 \mathrm{~cm}$ quartz cuvette. Inset displays visible region transitions.

\section{Conclusions}

Two new formamidinate-bridged $\mathrm{Rh}_{2}{ }^{\mathrm{IIII}}$ dimers that contain two bridging or bidentate chelating ligands were synthesized and characterized to better understand the effect of mode of 
ligand coordination on the electronic properties. The results show that both $c i s-\left[\mathrm{Rh}_{2}{ }^{\mathrm{IIII}}(\mu-\right.$ $\left.\mathrm{DTolF})_{2}(\mu-\mathrm{np})_{2}\right]^{2+}(3)$ and $c i s-\left[\mathrm{Rh}_{2}{ }^{\mathrm{II}, \mathrm{II}}(\mu-\mathrm{DTolF})_{2}\left(\kappa^{2}-\mathrm{dap}\right)_{2}\right]^{2+}(\mathbf{4})$ are relatively strong visible light absorbers which display low energy absorption far into the visible range. Electrochemistry and DFT calculations were used to assign the HOMO as a mixture of $\mathrm{Rh}_{2} /$ form character and the LUMO as predominately of diimine $\left(\pi^{*}\right)$ character. TD-DFT calculations for $\mathbf{3}$ and $\mathbf{4}$ predict the lowest energy singlet excited state to arise from the HOMO $\rightarrow$ LUMO transitions, whereby electron density from the $\mathrm{Rh}_{2}$ /form-based MO is transferred to the diimine $\left(\pi^{*}\right) \mathrm{MO}$. Conversely, TD-DFT calculations using $c i s-\left[\mathrm{Rh}_{2}{ }^{\mathrm{II}, \mathrm{II}}(\mu-\mathrm{DTolF})_{2}\left(\kappa^{2}-\mathrm{phen}\right)_{2}\right]^{2+} \quad$ (2) predict the $\mathrm{HOMO} \rightarrow \mathrm{LUMO}+3$ transition as the lowest energy singlet excited state, corresponding to $\mathrm{Rh}_{2} /$ form $\rightarrow \mathrm{Rh}_{2}\left(\mathrm{~d} \sigma^{*}\right)$. The results show that while the mode of diimine ligand coordination does play a role in the electronic structure of formamidinate-bridged $\mathrm{Rh}_{2}{ }^{\mathrm{IIII}}$ dimers, the observed absorption spectra are similar. The ability of $\mathbf{3}$ and $\mathbf{4}$ to absorb broadband, visible light make them well suited for photophysical applications such as solar energy conversion and photochemotherapeutics. Ongoing studies include the investigation of the excited state dynamics of these complexes using time-resolved spectroscopy, along with their photoreactivity.

\section{Corresponding Author}

*Authors to whom correspondence should be addressed: C. Turro: turro.1@osu.edu; K. R.

Dunbar:dunbar@mail.chem.tamu.edu; R.P.Thummel: thummel@uh.edu

\section{Acknowledgement}

C.T. and K.R.D. thank the U.S. Department of Energy, Office of Science, Office of Basic Energy

Sciences (CT: DE-SC0010542; KRD: DE-SC0010721) for their financial support of this 
research. The National Science Foundation supported the synthesis of the dap ligand by RPT (CHE-1465067).

\section{References}

[1] J.D. Knoll, C. Turro, Coord. Chem. Rev. 282-283 (2015) 110.

[2] S.J. Burya, A.M. Palmer, J.C. Gallucci, C. Turro, Inorg. Chem. 51 (2012) 11882.

[3] D.A. Lutterman, P.K.L. Fu, C. Turro, J. Am. Chem. Soc. 128 (2006) 738.

[4] L.E. Joyce, J.D. Aguirre, A.M. Angeles-Boza, A. Chouai, P.K.L. Fu, K.R. Dunbar, C. Turro, Inorg. Chem. 49 (2010) 5371.

[5] A.M. Palmer, J.D. Knoll, C. Turro, Dalton Trans. 44 (2015) 3640.

[6] A.M. Palmer, S.J. Burya, J.C. Gallucci, C. Turro, ChemMedChem 9 (2014) 1260.

[7] Z. Li, N.A. Leed, N.M. Dickson-Karn, K.R. Dunbar, C. Turro, Chem. Sci. 5 (2014) 727.

[8] D. Chartrand, G.S. Hanan, J. Phys. Chem. A 118 (2014) 10340.

[9] D. Chartrand, G.S. Hanan, Inorg. Chem. 53 (2014) 624.

[10] M.H. Chisholm, T.L. Gustafson, C. Turro, Acc. Chem. Res. 46 (2013) 529.

[11] B.G. Alberding, M.H. Chisholm, J.C. Gallucci, Y. Ghosh, T.L. Gustafson, Proc. Natl. Acad. Sci. U. S. A. 108 (2011) 8152.

[12] H. Chifotides, K. Dunbar, Rhodium Compounds, in: F.A. Cotton, C. Murillo, R. Walton (Eds.) Multiple Bonds Between Metal Atoms, Springer US, 2005, pp. 465.

[13] P. Piraino, G. Bruno, S. Lo Schiavo, F. Laschi, P. Zanello, Inorg. Chem. 26 (1987) 2205.

[14] J.C. Le, M.Y. Chavan, L.K. Chau, J.L. Bear, K.M. Kadish, J. Am. Chem. Soc. 107 (1985) 7195.

[15] T. Ren, C. Lin, E.J. Valente, J.D. Zubkowski, Inorg. Chim. Acta 297 (2000) 283.

[16] D.A. Lutterman, N.N. Degtyareva, D.H. Johnston, J.C. Gallucci, J.L. Eglin, C. Turro, Inorg. Chem. 44 (2005) 5388.

[17] J.L. Bear, C.L. Yao, R.S. Lifsey, J.D. Korp, K.M. Kadish, Inorg. Chem. 30 (1991) 336.

[18] G. Tresoldi, S. Lo Schiavo, F. Nicolò, P. Cardiano, P. Piraino, Inorg. Chim. Acta 344 (2003) 190.

[19] H.T. Chifotides, K.V. Catalan, K.R. Dunbar, Inorg. Chem. 42 (2003) 8739.

[20] S. Lo Schiavo, M.S. Sinicropi, G. Tresoldi, C.G. Arena, P. Piraino, J. Chem. Soc., Dalton Trans. (1994) 1517.

[21] T.A. White, S.E. Witt, Z. Li, K.R. Dunbar, C. Turro, Inorg. Chem. (in press).

[22] A. Chouai, S.E. Wicke, C. Turro, J. Bacsa, K.R. Dunbar, D. Wang, R.P. Thummel, Inorg. Chem. 44 (2005) 5996.

[23] K.V. Catalan, D.J. Mindiola, D.L. Ward, K.R. Dunbar, Inorg. Chem. 36 (1997) 2458.

[24] G.R. Fulmer, A.J.M. Miller, N.H. Sherden, H.E. Gottlieb, A. Nudelman, B.M. Stoltz, J.E. Bercaw, K.I. Goldberg, Organometallics 29 (2010) 2176.

[25] M.J. Frisch, G.W. Trucks, H.B. Schlegel, G.E. Scuseria, M.A. Robb, J.R. Cheeseman, G. Scalmani, V. Barone, B. Mennucci, G.A. Petersson, H. Nakatsuji, M. Caricato, X. Li, H.P. Hratchian, A.F. Izmaylov, J. Bloino, G. Zheng, J.L. Sonnenberg, M. Hada, M. Ehara, K. Toyota, R. Fukuda, J. Hasegawa, M. Ishida, T. Nakajima, Y. Honda, O. Kitao, H. Nakai, T. Vreven, J.A. Montgomery Jr., J.E. Peralta, F. Ogliaro, M.J. Bearpark, J. Heyd, E.N. Brothers, K.N. Kudin, V.N. Staroverov, R. Kobayashi, J. Normand, K. Raghavachari, A.P. Rendell, J.C. Burant, S.S. 
Iyengar, J. Tomasi, M. Cossi, N. Rega, N.J. Millam, M. Klene, J.E. Knox, J.B. Cross, V. Bakken, C. Adamo, J. Jaramillo, R. Gomperts, R.E. Stratmann, O. Yazyev, A.J. Austin, R. Cammi, C. Pomelli, J.W. Ochterski, R.L. Martin, K. Morokuma, V.G. Zakrzewski, G.A. Voth, P. Salvador, J.J. Dannenberg, S. Dapprich, A.D. Daniels, Ö. Farkas, J.B. Foresman, J.V. Ortiz, J. Cioslowski, D.J. Fox, Gaussian 09, in, Gaussian, Inc., Wallingford, CT, USA, 2009.

[26] A.D. Becke, Phys. Rev. A 38 (1988) 3098.

[27] C. Lee, W. Yang, R.G. Parr, Phys. Rev. B 37 (1988) 785.

[28] A.D. Becke, J. Chem. Phys. 98 (1993) 5648.

[29] W.J. Hehre, L. Radom, P.v.R. Schleyer, J.A. Pople, AB INITIO Molecular Orbital Theory, John Wiley \& Sons, New York, 1986.

[30] D. Andrae, U. Häußermann, M. Dolg, H. Stoll, H. Preuß, Theor. Chim. Acta 77 (1990) 123.

[31] B.E. Bursten, F.A. Cotton, Inorg. Chem. 20 (1981) 3042.

[32] R. Dennington, T. Keith, J. Millam, GaussView, Version 3, in, Semichem Inc., Shawnee Mission, KS, 2007.

[33] S. Fantacci, F. De Angelis, A. Selloni, J. Am. Chem. Soc. 125 (2003) 4381.

[34] P. Piraino, G. Tresoldi, F. Faraone, J. Organomet. Chem. 224 (1982) 305.

[35] Complexes $\mathbf{3}$ and $\mathbf{4}$ were synthesized with the starting material $c i s-\left[\mathrm{Rh}_{2}(\mu-\right.$ $\left.\mathrm{DTolF})_{2}(\mathrm{CH} 3 \mathrm{CN})_{6}\right]^{2+}(\mathbf{1})$, which is well established through crystallographic characterization to possess a cis-confirmation and does not undergo $\mu$-DTolF ligand rearrangements (see ref 23). Analogous cis- $\left[\mathrm{Rh}_{2}(\mu-\mathrm{DTolF})_{2}(\mathrm{NN})_{2}\right]^{2+}(\mathrm{NN}=$ bidentate diimine ligand $)$ complexes that use the same starting material, cis- $\left[\mathrm{Rh}_{2}(\mu-\mathrm{DTolF})_{2}(\mathrm{CH} 3 \mathrm{CN})_{6}\right]^{2+}$, have been synthesized and crystallographic data displays a cis confirmation (see refs 7,19 ).

[36] Axial $\mathrm{CH}_{3} \mathrm{CN}$ ligands of $\mathrm{Rh}_{2}$ (II,II) paddlewheel complexes readily exchange with the solvent. ${ }^{1} \mathrm{H}$ NMR of vacuum-dried samples of complexes $\mathbf{3}$ and $\mathbf{4}$ in $\mathrm{CD}_{3} \mathrm{CN}$ displays free $\mathrm{CH}_{3} \mathrm{CN}$ at $\delta=1.96 \mathrm{ppm}$ which corresponds to solvent-exchanged, axial $\mathrm{CH}_{3} \mathrm{CN}$ ligands (Chifotides, H. T.; Lutterman, D. A.; Dunbar, K. R.; Turro, C. Inorg. Chem. 2011, 50, 12099.

[37] R.S. Nicholson, I. Shain, Anal. Chem. 36 (1964) 706.

[38] A.J. Bard, L.R. Faulkner, Electrochemical Methods: Fundamentals and Applications, 2nd ed., Wiley, New York, 2001.

[39] A. Juris, V. Balzani, F. Barigelletti, S. Campagna, P. Belser, A. von Zelewsky, Coord. Chem. Rev. 84 (1988) 85.

[40] J.D. Aguirre, D.A. Lutterman, A.M. Angeles-Boza, K.R. Dunbar, C. Turro, Inorg. Chem. 46 (2007) 7494.

[41] C.S. Campos-Fernández, L.M. Thomson, J.R. Galán-Mascarós, X. Ouyang, K.R. Dunbar, Inorg. Chem. 41 (2002) 1523.

[42] Model complexes 2a, 3a, and 4a replaced $\mathrm{CH}_{3} \mathrm{CN}$ with $\mathrm{HCN}$ to reduce calculation time. . Major energy differences based on this change are not expected based on TD-DFT calculations performed for other $\mathrm{Rh}_{2}$ (II,II) complexes.

[43] R.J. Staniewicz, R.F. Sympson, D.G. Hendricker, Inorg. Chem. 16 (1977) 2166.

[44] T. Brietzke, W. Mickler, A. Kelling, U. Schilde, H.-J. Krüger, H.-J. Holdt, Eur. J. Inorg. Chem. 2012 (2012) 4632. 


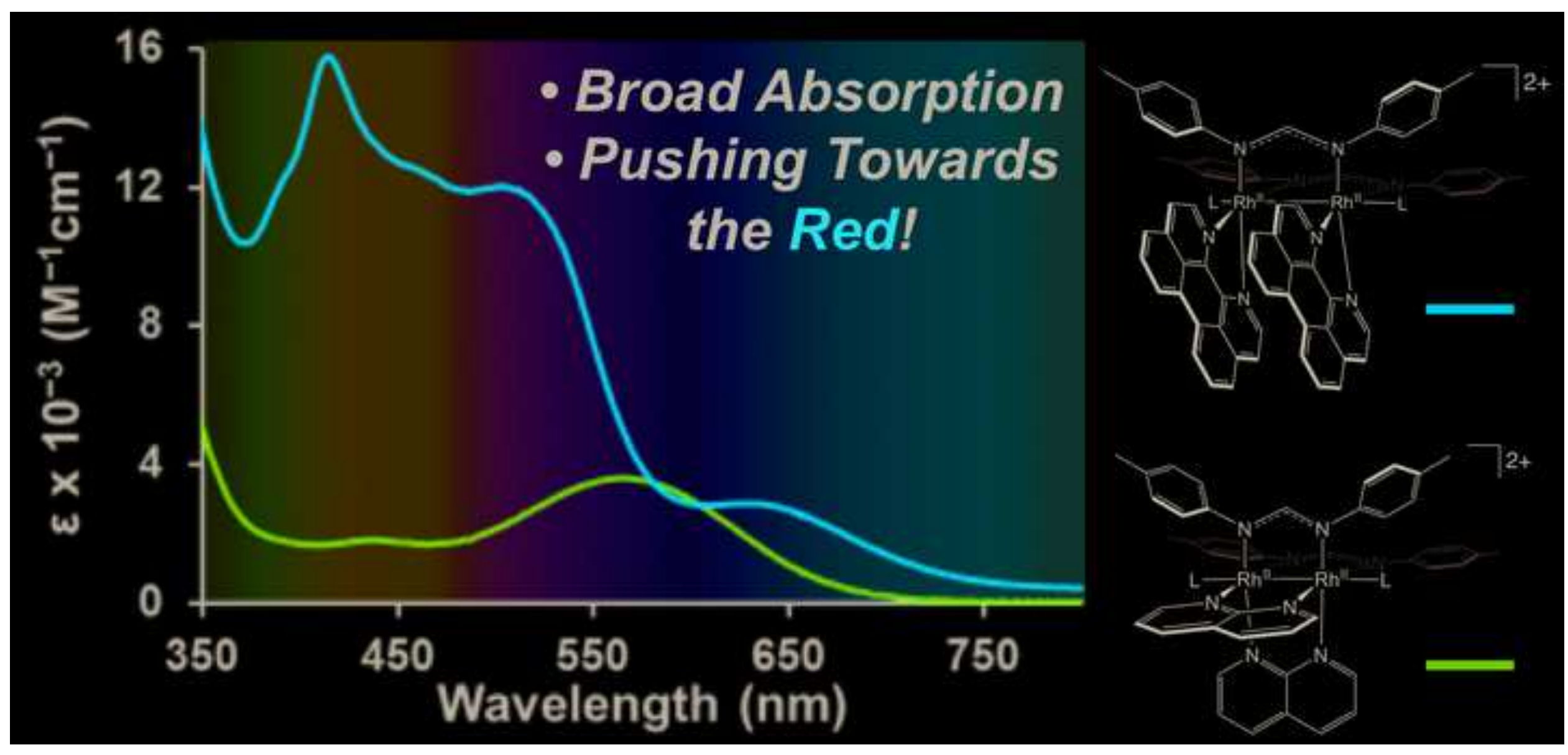




\section{Graphical Abstract - Synopsis}

The variation of the coordinated diimine ligand between bridging and bidentate chelating modes impacts the light absorbing and electronic properties of formamidinate-bridged $\mathrm{Rh}_{2}{ }_{2}^{\mathrm{IIII}}$ complexes. The two new complexes exhibit broad, strong absorption throughout the UV-visible range which can be useful for the efficient absorption of solar energy. 